\title{
AN ATTEMPT TO RECONCILE \\ THE DYNAMICAL AND RADAR DETER NINATIONS OF THE ASTRONOMICAL UNIT
}

\author{
By B. G. MARSDEN, \\ Yale University Observatory, New Haven, Connecticut.
}

RÉsumé. - L'auteur a pu obtenir une solution qui satisfait aussi bien les observations optiques que celles par radar, sans augmenter considérablement les résidus. Il s'ensuit que l'unité astronomique est déterminée de façon plus satisfaisante à l'aide des échos-radar sur Vénus que par la méthode dynamique seule. L'auteur ajoute quelques remarques sur les valeurs des masses de Mercure, Vénus et Mars.

Abstract. - It has been found possible to obtain a solution which satisfies both the dynamical and radar investigations without doing any great injustice to any of the observations. It is deduced that the astronomical unit is determined more satisfactorily from the radar bounces off Venus rather than by dynamical methods alone. Some comments are also given concerning the masses of Mercury, Venus and, Mars.

Zusammenfassung. - Es wurde dis Möglichkeit einer Lösung gefunden, die sowohl die dynamischen als auch die Radar-Untersuchungen befriedigt, ohne dass man dabei in grossen Widerspruch mit irgend einer Beobachtungen gerät. Man kann zeigen, dass die Astronomische Einheit befriedigender aus den Radio-Echos von Venus bestimmt wird als lediglich durch dynamische Methoden. Es werden auch einige Bemerkungen zu den Massen von Merkur, Venus und Erde gemacht.

Резюме. - Автор смог получить решение удовлетворяющие оптические наблюдения также как и наблюдения радаром, не увеличивая значительно остатки. Из этого следует, что астрономическая единица определена более удовлетворительным образом пользуясь радиоэхом Венеры нежели динамическим методом. Автор делает несколько замечаний о массах Меркурий, Венеры и Марса.

Several independent determinations of the astronomical unit from radar bounces off Venus in $196 \mathrm{I}$ agree to within about $1000 \mathrm{~km}$ of $149599000 \mathrm{~km}$. On the other hand, the best dynamical derivation - that by Rabe [1] from the motion of (433) Eros between r 926 and 1945 - leads to the grossly different value of $149527000 \pm 10000$ (m. e.) $\mathrm{km}$. There exist, however, strong correlations between some 
of the orbital elements of the Earth and Eros, and Eckstein [2] has resolved this difficulty by substituting into Rabe's equations the corrections to the Earth's orbital elements provided by Duncombe's [3] discussion of the observations of Venus; and he also assumed that no corrections were to be applied to Newcomb's value of the masses of Mercury, Venus and Mars. His results lead to a value for the astronomical unit of $149546000 \pm 2000 \mathrm{~km}$, and a very similar figure was obtained by assuming that Newcomb's values for the elements of the Earth's orbit were correct. Thus Eckstein found that it was easily possible to diminish the discrepancy between the dynamical and the radar values by some $26 \%$, and it was this discovery that motivated the greater part of this present investigation.

The discussion of the Lincoln Laboratory measurements by Pettengill et al. [4] shows that if Newcomb's orbits for Venus and the Earth are employed, there appears to be an increase in the value of the astronomical unit over the period covered by the range measurements.

If Duncombe's corrections to the orbital elements of Venus and the Earth are applied, this trend is diminished but is nevertheless still present. There are in addition small periodic variations with a period of about one month. It would seem desirable to attempt to remove the systematic trend, and to examine the periodic variation to ensure that it is not of a gravitational character, such as might be due to the omission of significant terms in Newcomb's tables. To eliminate any possible gravitational effect numerical integrations of the orbits of the two planets have been performed at the Jet Propulsion Laboratory, and these were adjusted so that the agreement with Newcomb's tables was as close as possible. In order to attend to the systematic variation a solution was made of Duncombe's normal equations groups 6 to 9, together with some afforded by the radar measurements. These groups pertain to optical observations of Venus made between 1886 and 1949 and Duncombe made solutions for the following 14 quantities :

$$
\begin{array}{ll}
\mathbf{A}=\frac{\mathbf{I}}{2}\left(\Delta \mathbf{M}_{0}+\Delta r-\Delta l^{\prime \prime}\right) ; & \mathbf{H}=\Delta \alpha+\Delta l^{\prime \prime} \\
\mathbf{B}=\frac{\mathbf{I}}{2} \Delta p ; & \mathrm{I}=\Delta \varepsilon ; \\
\mathbf{C}=\frac{\mathbf{I}}{2} \Delta q ; & \mathbf{J}=\Delta d_{\grave{\jmath}} ; \\
\mathbf{D}=e \Delta r+0.8 \Delta e^{\prime \prime}-\mathbf{I} .4 e^{\prime \prime} \Delta \varpi^{\prime \prime} ; & \mathbf{K}=\Delta d_{\alpha} ; \\
\mathbf{E}=\Delta e-\mathbf{I} .4 \Delta e^{\prime \prime}-0.8 e^{\prime \prime} \Delta \varpi^{\prime \prime} ; & \mathbf{L}=\frac{\mathbf{I}}{2} \Delta e^{\prime \prime} \\
\mathbf{F}=\frac{\Delta m}{5 m} ; & \mathbf{M}=\frac{\mathbf{I}}{2} e^{\prime \prime} \Delta \varpi^{\prime \prime} \\
\mathrm{G}=\Delta \grave{o}: & \mathbf{N}=\frac{\mathbf{I}}{4} \Delta l^{\prime \prime} .
\end{array}
$$


The doubly primed quantities refer to the usual orbital elements of the Earth and the unprimed ones to those of Venus. Thus A to E are principally connected with the orbit of Venus and $\mathrm{L}$ to $\mathrm{N}$ with that of the Earth.

No information about $F$ (one-fifth of the fractional correction to be applied to the mass of Mercury), G to I (concerned with corrections to the fundamental co-ordinate system), or $\mathrm{J}$ and $\mathrm{K}$ (corrections due to the phase of Venus) can be provided by the radar measurements, so Duncombe's equations were modified by substituting his values of these quantities, the secular variations being applied where relevant to bring them up to 1961.3 , the epoch of the radar observations. The 25 Lincoln Laboratory measurements furnish values of $:$, the one-way radar time to Venus, and we have

$$
=\lambda \Delta
$$

where $\Delta$ is the distance to Venus, and if this is measured in astronomical units and $\mathrm{I}$ is measured in milliseconds, $\mathrm{A}$ is the astronomical unit in light-milliseconds. Now,

$$
\begin{aligned}
d \tau & =\Lambda d \Delta+\Delta d \Lambda \\
& =\Lambda d \Delta+\Lambda Q \Delta
\end{aligned}
$$

where

$$
\mathrm{Q}=\frac{d \Lambda}{\mathrm{A}}
$$

and if $\mathrm{A}$ is assumed to be 499 ooo and $d \Delta$ and $\mathrm{Q}$ are measured in seconds of arc, we have

$$
d=2.41922(d]+0) \text {. }
$$

From the rectangular co-ordinates of the two planets

so that

$$
د^{2}=\left(x-x^{\prime \prime}\right)^{2}+\left(y-y^{\prime \prime}\right)^{2}+\left(z-z^{\prime \prime}\right)^{2} ;
$$

$$
d \Delta=\frac{x^{\prime}-x^{\prime \prime}}{\Delta} d\left(x-x^{\prime \prime}\right)+\frac{y^{\prime}-y^{\prime \prime}}{د} d\left(y-y^{\prime \prime}\right)+\frac{z-z^{\prime \prime}}{د} d\left(z-z^{\prime \prime}\right) .
$$

The differentials on the right-hand side of this equation may readily be expressed in terms of the usual elements and hence of the eight unknowns A to $\mathrm{E}, \mathrm{L}$ to $\mathrm{N}$, so that we have 25 equations of the form

$$
d==\iota \mathrm{A}+b \mathrm{~B}+c \mathrm{C}+d \mathrm{D}+e \mathrm{E}+\iota \mathrm{L}+m \mathrm{M}+u \mathrm{~N}+q \mathrm{Q}
$$

with

$$
q=2.41922 \Delta \text {. }
$$

The radar observations may be divided into four groups of different accuracies, and two assumptions were made about their relative weightings : that $\backslash \bar{w}$ for the four groups are $(a) 2,4,25,11$, and $(b) 1$, 
$2,5,3$. The relative weighting of the optical and radar measurements provides a more difficult problem, for whilst the former cover a period of 64 years and the latter only 3 months, the optical measurements do not give any information about the unknown $Q$ in which we are interested. Consequently, several trials were made, the results of some of them being given in table $\mathrm{I}$. We have

and taking

$$
d \mathrm{~A}=2.41922 \mathrm{Q}
$$

$$
\begin{gathered}
c=299.7925 \mathrm{~km} / \mathrm{ms} \\
d \Lambda=725.264 \mathrm{Q} \mathrm{km} .
\end{gathered}
$$

\begin{tabular}{|c|c|c|c|c|}
\hline$\sqrt{ } \bar{w}$ (radar).. & (a) & (b) & (a) & Optical \\
\hline$\sqrt{\bar{w}}$ (radar v. optical)... & $25: 1$ & $25: 1$ & $1: 1$ & only. \\
\hline$\Lambda$ & $\begin{array}{c}\prime \prime \prime \\
+0.301\end{array}$ & $\begin{array}{c}\prime \prime \prime \\
+0.275\end{array}$ & $\begin{array}{l}\prime \prime \\
+0.248\end{array}$ & $\begin{array}{r}{ }^{\prime \prime} \\
+0.21 \prime\end{array}$ \\
\hline B... & +0.160 & $+0.16 \mathrm{I}$ & $+0.16 \mathrm{I}$ & $+0.16 \mathrm{I}$ \\
\hline C... & +0.142 & +0.139 & +0.135 & $+0.13 j$ \\
\hline $\mathrm{D} \ldots \ldots \ldots \ldots$ & +0.076 & +0.080 & $+0.08 j$ & +0.085 \\
\hline E.. & +0.085 & +0.073 & +0.058 & +0.056 \\
\hline L... & -0.0I\% & -0.017 & $-0.03 \mathrm{I}$ & -0.033 \\
\hline M............ & -0.017 & -0.067 & -0.073 & -o.07í \\
\hline N............ & -0.045 & 一o.0们 & -0.0仿 & -0.015 \\
\hline$Q \ldots \ldots \ldots \ldots \ldots$ & +2.025 & $+2.00 ?$ & +9.131 & - \\
\hline
\end{tabular}

\section{Table I.}

Solutions of optical and radar data combined.

Table II.

\begin{tabular}{|c|c|c|c|c|c|c|c|}
\hline 1961. & & $\begin{array}{l}\text { ight distance } \\
\text { to Venus } \\
\text { (ms). }\end{array}$ & $\begin{array}{l}\text { a. u. } \\
(\mathrm{km}) .\end{array}$ & 1961. & & $\begin{array}{l}\text { ght distan } \\
\text { to Venus } \\
\text { (ms). }\end{array}$ & $\begin{array}{l}\text { a. u. } \\
(\mathbf{k m})\end{array}$ \\
\hline \multirow[t]{9}{*}{ Mar. } & $6 \ldots$ & -0.49 & -3 qo & $\Lambda_{\mathrm{pr}}$. & $10 \ldots$ & -0.03 & 一 \\
\hline & $7 \ldots$ & $-0.9^{3}$ & -670 & & $12 \ldots$ & +0.09 & +100 \\
\hline & $14 \ldots$ & -0.16 & -130 & & $12 \ldots$ & +0.19 & +200 \\
\hline & $16 \ldots$ & +0.01 & +30 & & $18 \ldots$ & +0.08 & +80 \\
\hline & $22 \ldots$ & -0.30 & -270 & & $20 \ldots$ & -0.03 & -30 \\
\hline & $23 \ldots$ & -0.49 & 一行o & & $21 \ldots$ & -0.03 & $-3 o$ \\
\hline & $24 \ldots$ & -0.13 & -120 & & $21 \ldots$ & $-0.0 I$ & - 10 \\
\hline & $27 \ldots$ & -0.66 & -630 & & $26 \ldots$ & 0.00 & o \\
\hline & 3 I ... & -0.37 & -370 & & $28 \ldots$ & 0.00 & o \\
\hline \multirow[t]{4}{*}{$\Lambda \mathrm{pr}}$. & $3 \ldots$ & -0.40 & 一年10 & Maý & $3 \ldots$ & +0.03 & +30 \\
\hline & $3 \ldots$ & -0.36 & -370 & & $16 \ldots$ & +0.40 & +280 \\
\hline & $5 \ldots$ & $-0.1 \%$ & -410 & & $\mathrm{I} 8 \ldots$ & +o.任 & $+? 00$ \\
\hline & $8 \ldots$ & -0.13 & -130 & & & & \\
\hline
\end{tabular}

Residuals of the Lincoln Laboratory radar measurements from the first solution in table $I$. 
Thus $\mathrm{Q}=+2.025$ corresponds to $d \mathrm{~A}=+1469 \mathrm{~km}$, and added to

$$
\Lambda=299 \cdot 7925 \times 499000=1 \text { 19596458 km }
$$

this gives $149597927 \mathrm{~km}$ for the astronomical unit. The values of $Q$ determined with other weighting-systems lead to values of the astronomical unit within $100 \mathrm{~km}$ of this, but if the uncertainty in $c$ is $0.5 \mathrm{~km} / \mathrm{s}$ that in $\mathrm{A}$ is $250 \mathrm{~km}$. The $(\mathrm{O}-\mathrm{C})$ residuals of the radar measurements from the first solution are given in table II and it may be noted that the monthly variation remains : no completely satisfactory explanation for this has been offered, the use of numerical integrations ruling out the possibility of a gravitational cause. It is quite possibly connected with variations in solar activity. A slight systematic effect also remains, and this may perhaps be due to solar variations of longer period.

In the work by Rabe on the motion of Eros the following unknowns were adopted :

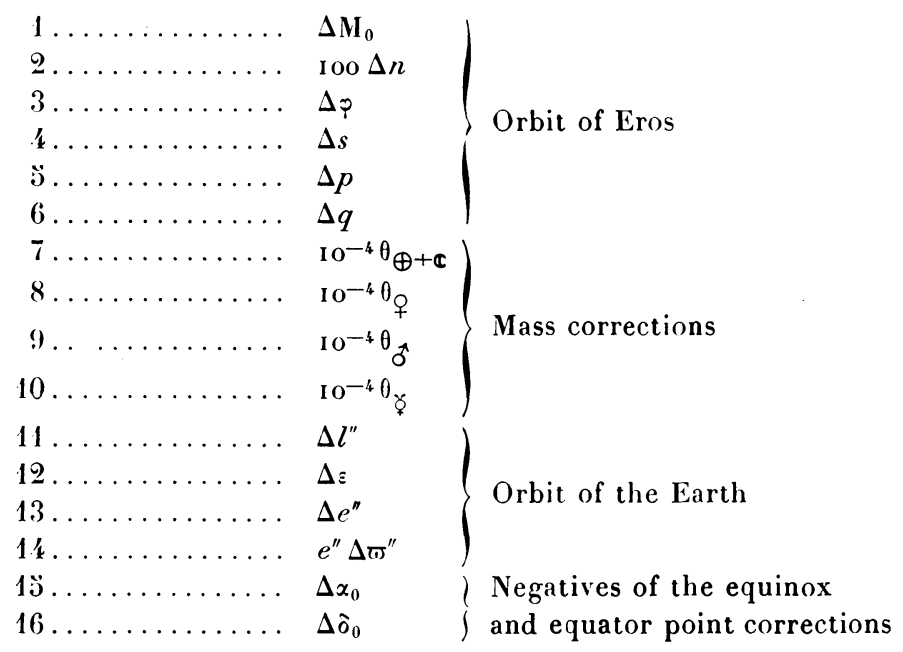

The mass corrections are applied by means of the relations

and

$$
\theta=20.6265 \theta
$$

$$
\frac{m_{0}^{-1}}{m^{-1}}=\mathrm{I}+\theta
$$

where the $m_{0}^{-1}$ are

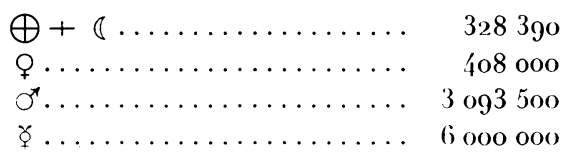


It was not possible to reconcile Rabe's observational equations with inis normal equations, but it is understood that the former are correct. The resulting reciprocal masses of the four inner planets are as follows, and Rabe's solutions are given for comparison :

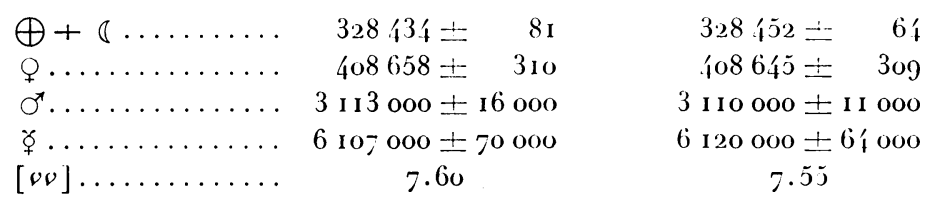

It was assumed that

$$
\pi: 3=\frac{2.236933 \times 10^{8}}{I+m_{\oplus+\Subset}^{-1}}
$$

the constant being consistent with that given by Brouwer [5] when $\mu^{-1}=8 \mathrm{I} .364$, though a rather smaller value is probable. An increase of 0.1 in $\mu^{-1}$ causes an increase of 33 in the last place of the constant. Thus the solution above corresponds to $\tau_{\odot}=8^{\prime \prime} .7983 \pm \mathrm{o}^{\prime \prime} .0007$, and taking the equatorial radius of the Earth as $6378 \mathrm{r} 66 \mathrm{~m} \mathrm{[6]}$, the astronomical unit becomes $149528000 \pm 12000 \mathrm{~km}$.

Rabe found corrections to the elements of the Earth's orbit which differ somewhat from those found from other sources. A comparison of the work by Duncombe on Venus, by Clemence in r 943 [7] on Mercury and by Morgan and Scott in 1939 [8] on the Sun gives the following values for the epoch 1932.7 (the mean date of the Eros observations) :

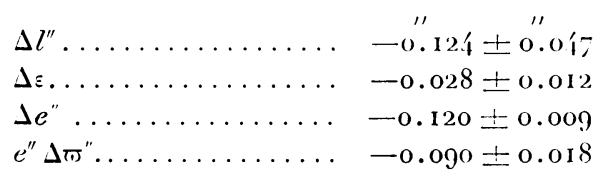

Similarly, a comparison of various determinations of the masses of Venus, Mars and Mercury gives the following values of their reciprocals :

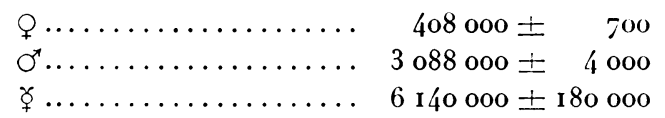

The seven equations provided by these data were then solved together with the 74 equations considered by Rabe. The reciprocal masses came out as follows :

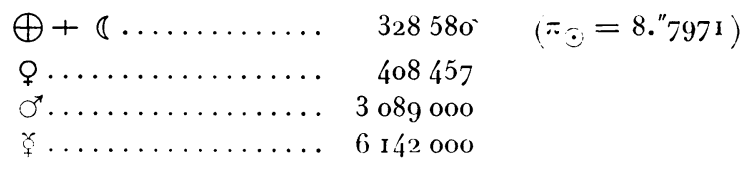


The [vv] of Rabe's equations is increased only to 8.57 , but the resulting $\tau_{\odot}$ is forced 0.3 of the way from the original solution to that determined from the radar measurements. Eckstein's value of 8 ". 79726 , obtained by direct substitution into Rabe's equations of Duncombe's values for the corrections to the Earth's orbital elements, is in very close accordance.

It is instructive to combine both the Eros and the Venus material into one solution. The number of independent unknowns is 23 , and it is convenient to take the 16 used by Rabe and to add to them the following from Duncombe's work on Venus :

$17: \mathrm{J} ; 18: \mathrm{K} ; 19: \mathrm{A} ; 20: \mathrm{B} ; 21: \mathrm{C} ; 22: \mathrm{D} ; 23: \mathrm{E}$.

Eight unknowns are common to the two investigations, and the relations between them are as follows :

$$
\begin{aligned}
& 7 \ldots \ldots \ldots \ldots \quad 10^{-40} \theta_{\oplus+\Phi}=-0.03145 .18-0.000299858 Q \\
& 10 \ldots \ldots \ldots \ldots \mathrm{10}^{-40} \theta_{\gamma}=103.132 \mathrm{~F} \\
& 11 \ldots \ldots \ldots \ldots \Delta l^{\prime \prime} \quad=4 \mathrm{~N} \\
& 12 \ldots \ldots \ldots \ldots \Delta \varepsilon \quad=\mathrm{I} \\
& 13 \ldots \ldots \ldots \ldots \Delta e^{\prime \prime} \quad=2 \mathrm{~L} \\
& 14 \ldots \ldots \ldots \ldots e^{\prime \prime} \Delta \pi^{\prime \prime}=2 M \\
& 13 \ldots \ldots \ldots \ldots \ldots \Delta x_{0} \quad=\mathrm{H}-4 \mathrm{~N} \\
& 16 \ldots \ldots \ldots \ldots, \Delta \delta_{0} \quad=\mathrm{G}
\end{aligned}
$$

For this purpose Duncombe's groups 8 and 9 only were utilized, the mean epoch being so close to that of the Eros observations that any secular changes in the orbital elements of the Earth could be ignored. Since the p. e. of unit weight for the Eros equations is \pm 0.2 .43 and that of Duncombe's Venus equations is $\pm o^{\prime \prime} .67$, the latter were multiplied by 0.36 prior to combining them with the former. The equation concerning the mass of Mars was also included. The resulting solution is given as solution A in table III and the residuals of the Eros equations are given in table IV. The corresponding values of the reeiprocal masses of the four inner planets agree very closely with the previous solution :

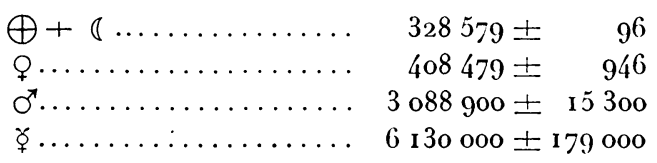

The orbital elements of Venus and the Earth are almost exactly what they would be if the Eros data were omitted, and since the relations between those elements of Eros prone to correlation with some of the Earth's are virtually eliminated, one would expect that the masses of 
the planets are determined rather more reliably. The resulting mass of the Earth-Moon system leads to :

$$
\pi_{\odot}=8 . " 797 \mathrm{I} \pm 0, " 0009, \quad \mathrm{~A}=\mathbf{1} 49549000 \pm \mathrm{I} 5000 \mathrm{~km} .
$$

The purely dynamical determination of the solar parallax could undoubtedly be improved by including observations made much earlier than 1926. Perhaps a better value could be provided by (1566) Icarus or (1620) Geographos, which can approach the Earth much more closely than can Eros. It may be of interest to note that the only other recent dynamical determination (that from Pioneer $V$ by the Space Technology Laboratory in 1960 ) is remarkably accordant with the above value :

$$
\bar{\tau}_{\odot}=8 . " 7974 \pm 0 . " \text { "оor } 2 .
$$

But these results are still very much at variance with the radar measurements. At this point it might be worth while to consider whether there could be any tremendous systematic error in these measurements. Smith [9] has noted that a reexamination of the i 959 records revealed

TABLE III.

\begin{tabular}{|c|c|c|c|c|c|}
\hline \multirow{2}{*}{ Jnknown. } & \multicolumn{2}{|c|}{ Solution A. } & \multicolumn{2}{|c|}{ Solution $\mathrm{B}$. } & \multirow{2}{*}{$\begin{array}{c}\text { Solution C. } \\
\text {-0.683 }\end{array}$} \\
\hline & $\begin{array}{c}\prime \prime \prime \\
-0.275\end{array}$ & $\begin{array}{l}\quad \prime \prime \\
+0.317\end{array}$ & $\begin{array}{c}\prime \prime \\
-0.607\end{array}$ & 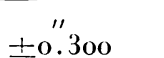 & \\
\hline $2 \ldots \ldots \ldots$ & +0.0436 & +0.0298 & $+0.000 \mathrm{I}$ & \pm 0.0268 & +0.02 (? \\
\hline $3 \ldots \ldots \ldots$ & -0.056 & \pm 0.085 & -0.071 & $\pm 0.08 i$ & -0.07 .1 \\
\hline 4........ & $-0.13 \mathrm{I}$ & +0.45 & +o.1? & $\div 0$-保 & +0.2 .33 \\
\hline ö....... & -0.08 .4 & $=-0.136$ & $-0.1 \% 4$ & \pm 0.135 & -0.111 \\
\hline $6 \ldots \ldots$ & $-0.1 \mathrm{II}$ & -0.088 & -0.118 & \pm 0.088 & -o.I?6 \\
\hline $7 \ldots \ldots$ & -0.0188ji & $=0.006063$ & -0.032017 & -0.00006 I & -0.03\%019 \\
\hline $8 \ldots \ldots$ & $-0.0 \%$ 往 & + +o.óng & +0.0509 & +o.ól9 & $-0.033 i$ \\
\hline 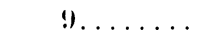 & $+0.03 I_{I}$ & \pm 0.103 & $+0.25 j$ & $\div 0.079$ & $+o .490$ \\
\hline $10 \ldots \ldots$ & -0.436 & \pm 0.573 & -1.328 & 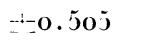 & -1.373 \\
\hline $11 \ldots \ldots$ & 一O.III & \pm 0.088 & -0.127 & \pm 0.088 & -0. I I 8 \\
\hline $12 \ldots \ldots \ldots$ & -0.04 & \pm 0.037 & -0.045 & \pm 0.037 & -0.045 \\
\hline $13 \ldots \ldots$ & $-0.08 \%$ & $\pm 0.05 ?$ & -0.069 & \pm 0.052 & -0.074 \\
\hline $14 \ldots \ldots$ & -0.107 & \pm 0.053 & -0.093 & $\pm 0.05 \%$ & -0.098 \\
\hline 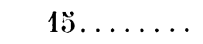 & +0.0 .43 & $\pm 0.09 ?$ & +0.060 & $\pm 0.09^{2}$ & +0.051 \\
\hline $16 \ldots \ldots$ & -0.099 & \pm 0.027 & -o.094 & \pm 0.027 & -0.094 \\
\hline $17 \ldots \ldots$ & +0.359 & \pm 0.026 & +0.357 & \pm 0.026 & +0.357 \\
\hline $18 \ldots \ldots \ldots$ & -0.553 & \pm 0.019 & -0.554 & \pm 0.019 & -0.554 \\
\hline $19 \ldots \ldots$ & +0.250 & \pm 0.018 & +0.256 & \pm 0.018 & +0.256 \\
\hline $20 \ldots \ldots$ & +0.059 & $\pm 0.02 \mathrm{I}$ & +o.o6o & \pm 0.021 & +0.060 \\
\hline $21 \ldots \ldots$ & +0.017 & \pm 0.029 & +o.org & \pm 0.028 & +0.019 \\
\hline $22 \ldots \ldots \ldots$ & +0.050 & $=0.023$ & +o.049 & \pm 0.023 & +o.049 \\
\hline $23 \ldots \ldots \ldots$ & $+0.1 \% 0$ & $=--0.021$ & +0.123 & $\therefore 0.021$ & +o.r.' \\
\hline
\end{tabular}

Solutions of Eros and Venus equations combined. 
TABLE IV.

Residuals of Eros observations.

\begin{tabular}{|c|c|c|c|c|c|c|c|c|}
\hline \multirow{2}{*}{\multicolumn{2}{|c|}{$\begin{array}{c}\text { Date } \\
0^{\mathrm{h}} \mathrm{E} . \mathrm{T} \text {. }\end{array}$}} & & \multicolumn{2}{|c|}{ Solution $\boldsymbol{A}$. } & \multicolumn{2}{|c|}{ Solution B. } & \multicolumn{2}{|c|}{ Solution C. } \\
\hline & & & $x \cos \bar{\delta}$ & $\Delta \delta$. & $\Delta x \cos \hat{\delta}$ & $\Delta i j$. & $\alpha \cos \delta$ & $\Delta \bar{j}$. \\
\hline 1926. & July & $1 \ldots . .$. & -0.13 & $-0.0,1$ & $\begin{array}{c} \\
+0.20\end{array}$ & $\begin{array}{r}\prime \prime \prime \\
+0.7 \%\end{array}$ & $\begin{array}{r}\prime \prime \\
+0.35\end{array}$ & $\begin{array}{l}\text { +o.8 } \\
+\end{array}$ \\
\hline 1928. & Sept. & Io.... & $-0 . \%$ & -0.57 & -0.69 & -0.87 & -1.02 & -1.0 \\
\hline \multirow[t]{9}{*}{1930.} & Oct. & $10 \ldots$ & +0.11 & -0.20 & -0.04 & -0.14 & +0.05 & -0.1 \\
\hline & & $20 \ldots \ldots$ & +0.39 & $-0.0 \%$ & $+0.2 \mathrm{I}$ & +0.08 & +0.32 & +0. \\
\hline & & $30 \ldots$ & +0.96 & +0.03 & +0.09 & +0.18 & $+0.2 \%$ & +0.1 \\
\hline & Vor. & $9 \ldots \ldots$ & $+0.1 i$ & $+0 . \%$ & +0.01 & +0.38 & $+0.1 \%$ & +0.33 \\
\hline & & $19 \ldots$ & +o.19 & $-0.2 ;$ & +0.09 & $-0.0 i$ & +0.21 & $-0.1^{\circ}$ \\
\hline & & $29 \ldots$ & +0.18 & $+0.1 \%$ & +0.11 & $+0.3 i$ & +0.27 & $+0 .$. \\
\hline & Dec. & $9 \ldots \ldots$ & +0.29 & $-0.0)$ & $+0.2 i$ & +0.18 & +0.10 & +0.1 \\
\hline & & $19 \ldots$ & -0.33 & $+0 . \cdots 3$ & $-0.3 i$ & +0.1 & $-0.2 \mathrm{I}$ & +0 \\
\hline & & $29 \ldots$ & +0.17 & +0.31 & +0.17 & +0.13 & +0.29 & +0 \\
\hline \multirow[t]{12}{*}{$19: 31$} & Ian. & $s \ldots$ & +0.3 & -0.01 & $+0.2 I$ & $+0.0 \%$ & $+0.3 \%$ & -0.1 \\
\hline & & I $8 \ldots$ & -0.18 & +0.31 & $-0 . \%$ & +0.30 & -0.1' & +0.1 \\
\hline & & $28 \ldots$ & -0.30 & $+0 \cdot)^{\prime}$ & -0.36 & +0 & $-0.3 \%$ & +0.1 \\
\hline & Feb. & $\tau \ldots \ldots$ & +o.13 & -0.?; & +0.08 & -0 & +0.08 & -0.3 \\
\hline & & $1-\ldots$ & -0.53 & $-0.3 \mathrm{I}$ & -0.54 & -0.37 & -0.57 & -0.3 \\
\hline & & $27 \ldots$ & $-0.0 i$ & -0.30 & $-0.0 \mathrm{I}$ & -0.3 & -0.07 & -0.2 \\
\hline & Mar. & $9 \ldots$ & $+0.1 \%$ & -0.18 & +0.19 & -0.16 & $+0.1 \%$ & -0.1 \\
\hline & & I9.... & 0.00 & $-0.0 i$ & +0.08 & +0 . & 0.00 & +0. \\
\hline & & $29 \ldots$ & +0.28 & -0.10 & +0.31 & -0.01 & +0.27 & +0.0 \\
\hline & Apr. & $8 \ldots \ldots$ & +0.16 & -0.96 & +0.19 & -0.13 & $+0.1 ?$ & -0.0 \\
\hline & & $18 \ldots$ & +0.20 & -0.17 & $+0 . \%$ & $-0.0 \%$ & +0.15 & +0.0 \\
\hline & & $28 \ldots \ldots$ & +o. 仁 & +0.03 & +o.们 & +0 & +o.11 & +0. \\
\hline \multirow[t]{3}{*}{1933.} & llar. & $26 \ldots$ & $-1.0 i$ & +0.7 & -0.97 & +0 & $-0.9^{1}$ & +0.4 \\
\hline & May & $31 \ldots$ & -0.16 & -0.18 & +0.08 & $+c$ & +0.28 & +0.0 \\
\hline & Aug. & I 1 ...... & -0.21 & -0 . & 1, & -0 & 0.19 & -0.0 \\
\hline \multirow[t]{3}{*}{$1933 \%}$. & July & $1 \% \ldots$ & -0.31 & -0.10 & -0.14 & $\cdots o$. & -0.16 & -0. \\
\hline & lig. & $25 \ldots$ & $+0.8 i$ & +0.63 & +1.17 & $+o$. & +0.88 & +0.7 \\
\hline & Nov. & $9 \ldots$ & +0.70 & $+0 . P 7$ & +0.91 & +0 & $+0.7 \%$ & +0.3 \\
\hline $193 \bar{~}$. & Nov. & $3 \ldots$ & +0.00 & -0.13 & +2.20 & -0.39 & +0.77 & -0.27 \\
\hline \multirow[t]{2}{*}{1938.} & Jan. & I. & -0.29 & -0.5 & -0.07 & -o.4í & -0.40 & $-0.4 !$ \\
\hline & Feb. & $93 \ldots$ & $+0 . j 0$ & $+o$. & +0.54 & +0 & +0.33 & +0.0 \\
\hline 1940. & July & $30 \ldots$ & -0.59 & -0.34 & -1.16 & -0.33 & -1.38 & -0.37 \\
\hline 1942. & Aug. & $13 \ldots$ & -0.28 & -0.06 & -0.89 & -0.47 & -0.03 & -0.0 \\
\hline 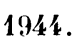 & Sept. & $15 \ldots$ & $+o .43$ & +0.26 & -1 . & -0 . & +0.20 & +0.1 \\
\hline & Nov. & 3o.... & +o IJ & +0.17 & -0.08 & +0.08 & +o 16 & +03 \\
\hline $9 \mathbf{y}$. & Feb. & $2 \ldots$ & -0.58 & -0.03 & $-0.3 \%$ & -0.07 & -0.78 & -0.1 \\
\hline
\end{tabular}

an echo from Venus corresponding to that value of the astronomical unit determined from the I 96 I bounces, and Peabody [10] has reported that the preliminary results from the 1962 inferior conjunction also confirm 
those of $\mathrm{I} 96 \mathrm{I}$, the recent measurements yielding a value perhaps some $800 \mathrm{~km}$ greater. Kotelnikov [11] has succeeded in contacting Mercury by radar and the resulting measurements are in accord with his value of $149599300 \mathrm{~km}$ for the astronomical unit determined from Venus in $196 \mathrm{I}$.

But the most definite argument that the radar information is essentially correct (in particular, that the assumption that propagation takes place with the speed of light in vacuo is satisfactory) is that the value thus provided for the distance of the Moon is in excellent agreement with that derived by other methods; and that even if it is in error by $2 \mathrm{~km}$ it would be unlikely to leave an uncertainty exceeding $500 \mathrm{~km}$ in the case of Mercury near inferior conjunction.

It is now therefore necessary to see how well the radar parallax satisfies the Eros equations. Rabe [12] has solved his equations forcing $m_{\oplus+\leftarrow}^{-1}$ to be 328906 , and finds that $[v v]$ is increased to 22.29 , that many residuals are greater than $\mathrm{I}^{\prime \prime}$ and that there are conspicuous systematic tendencies. We have solved the radar equations in conjunction with those provided by Duncombe and Rabe, the difference in epoch being allowed for, and the equations multiplied by $v \bar{w}=2.78$. Tables III and IV, solution B, give the results and residuals, but the residuals can scarcely be described as satisfactory, $[v v]$ being 20.72 . Unknowns 7 to 10 lead to the following values of the reciprocals of the planetary masses :

$$
\begin{aligned}
& \oplus+8 \ldots 328900.5 \pm 1.0 \quad \sigma^{7} \ldots \ldots \ldots 3055700=11500 \\
& \text { q......... } 406996 \pm 823 \quad \Varangle \ldots \ldots \ldots .6413000 \pm 1(\text { 1 } 1000
\end{aligned}
$$

and we should have

$$
\tau_{\odot}=8 .^{\prime \prime} 794188 \pm 0 . " 000009, \quad \Lambda=149597800 \pm 150 \mathrm{~km}
$$

though these mean errors are those actually resulting from the equations as solved and are consequently extremely conservative. This value of the mass of Venus is in very good agreement with that determined by Morgan and Scott [8] from their discussion of observations of the Sun. This value of the mass of Mercury is in remarkable agreement with those determined from the secular variations of the orbits of Mercury and the Earth by Clemence [13] and Brouwer [14], namely, $m_{\square}^{-1}=6400000$ and 6430000 respectively, where the latter's value has been adjusted on account of the change indicated in the mass of the Earth-Moon system. Duncombe's [3] value of 5970000 has a greater uncertainty, particularly if one compares the values furnished by his groups of equations individually. The close agreement between Duncombe's value and that determined from Encke's comet by Makover and Bokhan [15] is perphaps fortuitous, the latter being the weighted mean of $5885000 \pm 300$ ooo (from observations 
between 1898 and $\mathrm{r} g \mathrm{r}$ ) and $6280000 \pm 500$ ooo (from observations between 1937 and 1954), but apart from the obvious difficulties associated with observations of a diffuse object this latter method of determination depends heavily on the secular changes in the mean motion of the comet, some doubt having been expressed by Roemer [16] as to whether they actually exist. The value for Mars from solution B does not seem very reasonable, but it might be argued that this quantity is not well determined from these observations of Eros. Consequently, it is of interest to transfer it to the right-hand sides of the equations and then to see if a value can be assigned which leaves a satisfactory set of residuals. Thus there results solution C (see tables III and IV), in which $[v v]$ is only $\mathrm{i} 3.73$. For the reciprocal masses :

$$
\begin{aligned}
& \oplus+8 \ldots 328900.5 \quad \sigma^{7} \ldots \ldots \ldots 302 \mathrm{I} 700 \\
& \text { q....... } 40866.4 \quad \Varangle \ldots \ldots \ldots \quad 6.430000
\end{aligned}
$$

that of Venus having returned to its former value and that of Mars being understandably quite wild.

This last solution appears to be reasonably acceptable and a reconciliation between dynamics and radar has been achieved. One might still have qualms about the mass of Mars. But do we really know the mass of Mars as accurately as is claimed? Newcomb [17] adopted the value $m_{\sigma^{4}}^{-1}=3093500$ determined by Hall in 1878 from the satellites, stating that he did not think it could be in error by more than one fiftieth part; the value from solution $\mathrm{C}$ differs from Hall's by one forty-third part. Van den Bosch [18] arrived at a value of 3088 ooo \pm 7 ooo as an average of 27 determinations from the satellites between 1877 and 1909 , but drew no distinction between the direct measurements of position angle and distance of a satellite from the estimated center of the Martian disk i 2 or 13 magnitudes brighter and the measurements relative to the Martian limbs. The measurements of this second type are much more consistent and yield values of $m_{\sigma^{7}}^{-1}$ quite significantly smaller than those of the first :

$$
\begin{aligned}
& \text { From center. From limbs. } \\
& \text { Phobos.............. } 3 \text { 107 } 000 \quad 3078000 \\
& \text { Deimos.............. } 3092000 \quad 3080000
\end{aligned}
$$

Systematic errors are undoubtedly present, and it would seem that the only sure way of eliminating them is to measure the relative positions of the satellites photographically, leaving Mars out of the picture entirely. Photographs taken by Kuiper with the 82 -inch reflector in 1956 have recently been measured and reduced by van Biesbroeck [19] A further promising opportunity for determining the mass of Mars is offered by a study of the motion of (1011) Laodamia [20]. 
An extension of the calculation from the secular variations by Brouwer [13] using also the observations of Venus produces the following values for the reciprocals of the planetary masses :

$$
\text { ㅇ : } 408800 \pm 1500 ; \quad \sigma^{7}: 3092000 \pm 39000 ; \quad \Varangle: 6260000 \div 510000 .
$$

but one would have greater confidence in the use of secular variations if a combined discussion could be made of all the observations of the four inner planets, and perhaps the principal asteroids too.

Acknowledgments. - I should like to thank Dr. D. Brouwer for instigating this study and for numerous recommendations and suggestions during its progress. Helpful advice has also arisen from discussions with Dr. G. M. Clemence and Dr. R. L. Duncombe. My thanks are also due to Dr. P. R. Peabody and the Jet Propulsion Laboratory for the results of their numerical integrations of the motions of Venus and the Earth. Most of the calculations in this paper were performed on the I.B. M. 1620 in the Yale Computer Center and in this respect financial support from the National Aeronautics and Space Administration is hereby gratefully acknowledged.

\section{REFERENCES.}

[1] E. Rabe, Astron. J., vol. 55, 1950, p. I 12.

[2] M. C. Eckstein, Astron. J., vol. 68, 1963, p. 23 I.

[3] R. L. Duncombe, Astron. Papers Amer. Ephemeris, vol. 16, 1958, part 1.

[4] G. H. Pettengill, H. W. Briscoe, J. V. Evans, E. Gehrels, G. M. Hyde, L. G. Kraft, R. Price and W. B. Smith, Astron. J., vol. 67, 1962, p. I8I.

[5] D. Brouwer, I. A. U. Symposium No. 21, (Bull. Astron.t. XXV, p. 250 ).

[6] I. Fischer, J. Geophys. Res., vol. 65, i 960 , p. 2067.

[7] G. M. Clemence, Astron. Papers Amer. Ephemeris, vol. 11, 19'3, part 1.

[8] H. R. Morgan and F. P. Scott, Astron. J., vol. 47, г939, p. 193.

[9] W. B. Sмiтh, Astron. J., vol. 68, г963, p. 15.

[10] P. R. Peabody, Personal communication, $19^{63.3 .}$

[11] V. A. Kotelnikov, Dokl. U.S. S. R. Acad. Sc., vol. 147, 1962, p. 1320.

[12] E. Rabe, I. A. U. Symposium No. 21, (Bull. Astron.t. XXV, p. 220).

[13] G. M. Clemence, Proc. Amer. Philosoph. Soc., vol. 93, i949, p. ;.

[14] D. Brouwer, Bull. Astron., vol. 15, i950, p. 177.

[15] S. G. Makover and N. A. Bokhan, Trudy Inst. Theor. Astron. Leningrad, vol. 8, I 96 I, p. I 35 .

[16] E. Roemer, Astron. J., vol. 66, 1961, p. 368.

[17] S. Newсомв, The elements of the four Inner planets and the Fundamental constants of Astronomy, Washington Government Printing Office, r 895 , p. 99.

[18] C. A. van Den Bosch, De Massa's van de Groote planeten, University of Utrecht Dissertation, 1927 , p. 126.

[19] G. van Biesbrook, Personnal communication, 1963.

[20] E. RABE, Astron. J. vol. 64, 1959, p. 344. 